\title{
Beta-ketothiolase deficiency: An unusual cause of recurrent ketoacidosis
}

\author{
Gonca Kılıç-Yıldırım ${ }^{1}$, Sultan Durmuş-Aydoğdu², Serdar Ceylaner ${ }^{3}$, Jörn Oliver Sass ${ }^{4,5}$ \\ ${ }^{1}$ Pediatric Nutrition and Metabolism Unit, Eskisehir State Hospital, Eskişehir; ${ }^{2}$ Pediatric Nutrition and Metabolism Unit, \\ Osmangazi University Faculty of Medicine, Eskisehir; ${ }^{3}$ Medical Geneticist, Intergen Genetics Centre, Ankara, Turkey; \\ ${ }^{4}$ Clinical Chemistry and Biochemistry and Children's Research Center, University Children's Hospital, Zürich, Switzerland; \\ ${ }_{5}^{5}$ Bioanalytics and Biochemistry, Department of Natural Sciences, Bonn-Rhein Sieg University of Applied Sciences, Rheinbach, \\ Germany.E-mail: goncaklch@yahoo.com
}

Received: 18th January 2017, Revised: 16th February 2017, Accepted: 20th February 2017

SUMMARY: Kılıç-Yıldırım G, Durmuş-Aydoğdu S, Ceylaner S, Sass JO. Betaketothiolase deficiency: An unusual cause of recurrent ketoacidosis. Turk J Pediatr 2017; 59: 471-474.

Beta-ketothiolase deficiency (mitochondrial acetoacetyl-CoA thiolase, MAT or T2 deficiency) is a rare autosomal recessive disorder of isoleucine and ketone body metabolism due to acetyl-CoA acetyltransferase-1 (ACAT1) gene mutations. The disease is characterized by recurrent episodes of ketoasidosis which starts with vomiting and followed by dehydration and tachypnea. Here, we present a patient who was admitted to the hospital with severe acidosis and dehydration because of vomiting induced by protein rich nutrient and was diagnosed with MAT deficiency. 3-hydroxy-butyric acid, acetoacetic acid and 3-hydroxy-iso-valeric acid levels were significantly increased and tiglyglycine as trace amount in the urine organic acid analysis of the patient. Genetic analysis for ACAT-1 showed compound heterozygosity for the mutations c.949G >A (p.D317N) and c.951C>T (p.D317D), which both are known to cause exon 10 skipping and to be pathogenic missense mutations.

Key words: recurrent ketoacidotic episodes, keton bodies, tiglyglycine, isoleucine metabolism.

Beta-ketothiolase deficiency (mitochondrial acetoacetyl-CoA thiolase MAT or T2 deficiency) is a rare autosomal recessive disorder of isoleucine and ketone body metabolism. SuccinylCoA: 3-oxoacyl-CoA transferase (SCOT) and MAT are the main ketolytic enzymes. ${ }^{1,2}$ This disorder was first described in 1971 by Daum et al. ${ }^{3}$ and more than 100 patients are known..$^{2,3}$ The responsible gene ACAT1 is located on chromosome 11q22.3-23.1. ${ }^{4}$ MAT deficiency is not found reliable in newborn screening. 5,6 The incidence was reported as 1 in 232,000 taking into account missed cases by newborn screening in Minnesota, USA. ${ }^{6}$

MAT deficiency is characterized by recurrent attacks of ketoacidosis. Neonatal onset is rare. Patients are generally asymptomatic between episodes. Dehydration, hyperventilation, lethargy, coma and death may occur during the episodes.

Here, we present a patient with MAT deficiency.
Organic acid analysis is diagnostic for this disorder. However, in the present case, urinary organic acid analysis has shown only subtle findings even during severe ketoacidotic episode.

\section{Case Report}

A twenty-two-month-old boy was admitted to the hospital with severe metabolic acidosis and dehydration because of vomiting induced by protein rich nutrient. He had three episodes of severe acidosis and required hospital admission for parenteral alkaline therapy before. He was the first child of non-consanguineous parents. He had normal growth and development. In physical examination he was lethargic, dehydrated, tachypneic and had acetone odor. Clinical test showed, blood glocose 65 $\mathrm{mg} / \mathrm{dl}$, sodium $139 \mathrm{mEq} / \mathrm{L}$, potasium 3.85 $\mathrm{mEq} / \mathrm{L}$, chlorine $104 \mathrm{mEq} / \mathrm{L}$, BUN $37.2 \mathrm{mg} /$ $\mathrm{dl}$, creatinine $0.52 \mathrm{mg} / \mathrm{dl}$, uric acid $13.9 \mathrm{mg} /$ 
dl, blood ammonia $108 \mu \mathrm{g} / \mathrm{dl}$, lactate $15 \mathrm{mg} /$ $\mathrm{dl}$ and pyruvate $0.9 \mathrm{mg} / \mathrm{dl}$. Venous blood gas analysis showed a $\mathrm{pH}$ of $7.26, \mathrm{PCO}_{2} 17.9$ $\mathrm{mmHg}$, bicarbonate $7.8 \mathrm{mmol} / \mathrm{L}$, base excess $-18.2 \mathrm{mmol} / \mathrm{L}$. Urine ketone was $4(+)$. He was treated with intravenous alkaline therapy, L-carnitine, biotin and vitamin B12 due to suspicion of organic acidemia. Urinary ketones became negative and the blood gas data was normal on the second day and then oral Shohl solution was started. Branched chain amino acid levels in urine were elevated on one sided paper chromatography. Blood acylcarnitine analysis was normal. 3-hydroxy-butyric acid, acetoacetic acid and 3-hydroxy-iso-valeric acid levels were significantly increased and tiglyglycine as trace amount in the urine organic acid analysis. The result of the enzyme assays in lymphoblast homogenates (obtained from lymphocytes immortalized with Epstein Barr virus) provided no indication for the ketolysis defect SCOT deficiency (SCOT activity: 14.1 $\mathrm{nmol}$ acetoacetyl-CoA $\mathrm{min}^{-1} \mathrm{mg}^{-1}$ protein, which closely resembles activities of the negative controls, while no detectable activity was found in a SCOT deficient positive control), but the data did not exclude methylacetoacetyl-CoA thiolase (MAT; 'beta-ketothiolase') deficiency, which would be detected in a more reliable manner in cultivated fibroblasts, which were not available. Because of the small amount of tiglyglycine in the urinary organic acids, we then approached a diagnostic work-up towards MAT deficiency on the gene level. Mutation analysis of the ACAT1 gene showed heterozygosity for the mutations c.949G $>$ A (p.D317N) and c.951C > T (p.D317D). After the diagnosis of T2 deficiency, the patient was treated with oral Shohl solution, L-carnitine and low isoleucine diet. There was no new episode under this treatment during a followup period of 32 months.

Written informed consent was obtained from the parents of the patient for publication of this case report.

\section{Discussion}

Most patients with T2 deficiency present during the first two years of life, but some of them remain asymptomatic into adulthood. ${ }^{7}$ Episodes of acute illness are induced most commonly by infections and other cause of catabolism. They can also be induced by high protein intake. During episodes of acute illness, patients often require admission to hospital and parenteral alkaline fluid therapy. The frequency of episodes diminishes by age. Intellectual development is generally normal, but some have mental retardation, speech problems, ataxia, chorea or dystonia with abnormalities in the basal ganglia on MRI. ${ }^{8-11}$ A few patients have seizures, especially during acute episodes. ${ }^{12}$ Severe central hypotonia and congestive cardiac myopathy were also reported.9,13,14

The case was at twenty-two months of age at first presentation. It seems that high protein intake was the triggering factor for the last episode in the patient. He had three episodes of severe acidosis and required admission to the hospital for parenteral alkaline fluid therapy. He had normal growth and development and normal cardiac functions.

In most patients, blood glucose, lactate and ammonia concentrations are normal, but there may be hypoglycemia or hyperglycemia. ${ }^{15,16}$ Amino acid concentrations are usually normal but sometimes branched chain amino acid levels are elevated, as in our patient.

We suspected ketolysis defect or other ketoacidotic states because of recurrent ketoacidotic episodes history, metabolic acidosis, acetone odor and highly elevated keton bodies in urine in our patient on admission. 3-hydroxy-butyric acid, acetoacetic acid and 3-hydroxy-iso-valeric acid levels were increased significantly and tiglyglycine was detected in trace amounts in the urine organic acid analysis.

Clinical findings are similar in deficiencies of beta-ketothiolase and succinyl-CoA 3-oxoacid CoA transferase (SCOT), another ketolytic enzyme. In the acute decompensation, the latter usually presents with the urinary organic acid pattern with high concentrations of 3-hydroxy-n-butyrate and acetoacetate only. In addition, 2-methyl-3-hydroxybutyrate, 2-methylacetoacetate and tiglicylate are typically found in MAT deficiency.

Because organic acid findings were initially not considered typical for MAT deficiency we excluded SCOT deficiency in our patient first and only latter approached genetic analysis for MAT deficiency because of a trace amount of tiglyglycine in the urine organic acid analysis. 
Blood acylcarnitine analysis generally shows increased 2-metyl-3-hydroxybutrylcarnitine (C5-OH acylcarnitine) and tiglylcarnitine (C5:1 acylcarnitine) in MAT deficiency, although this is not a consistent finding. ${ }^{17}$ Acylcarnitine levels were within normal limits in our patient during the ketoacidotic episode.

Mutation analysis for ACAT-1 showed compound heterozygosity for the mutations c.949G $>$ A (p.D317N) and c.951C>T (p.D317D). While the latter mutation may be mistaken as a silent mutation, both sequence variants have been demonstrated to cause exon 10 skipping and to be pathogenic missense mutations. ${ }^{18,19}$ DNA of the parents has also been studied: The patient's mother was heterozygous for c.949G $>$ A (p.D317N), and his father was heterozygous for c.951C > T (p.D317D) mutation.

The absence of detectable tiglyglycine suggests a biochemically mild phenotype, with some residual activity ${ }^{2}$, which -in this case- may be explained by the production of some normally spliced mRNA. ${ }^{18}$

During acute attacks in MAT deficiency, immediate correction of hypoglycemia is needed, followed by constant high-rate glucose infusion. ${ }^{12}$ Alkalinisation should be considered in a very pronounced acidosis as should the administration of L-carnitine if its blood level is low. For prevention of metabolic decompensations fasting must be avoided. An additional bedtime snack and mild protein restriction should be considered and potential L-carnitine deficiency compensated. ${ }^{12}$

MAT deficiency is a life-threatening disease and should be considered in the differential diagnosis of ketoacidosis. Early diagnosis and management can prevent recurrent episodes. Patients with MAT deficiency who have a mild mutation with some residual activity may show subtle abnormality in urine organic acid analysis and normal acylcarnitine profiles even during acute ketoacidotic episodes.

\section{Acknowledgements}

We are grateful to Ms Luzy Bähr for excellent technical assistance and the Fondation Claude \& Giulina (Vaduz, Liechtenstein) for laboratory equipment. We would like to thank the patient and his family.

\section{REFERENCES}

1. Sass JO. Inborn errors of ketogenesis and ketone body utilization. J Inherit Metab Dis 2012; 35: 23-28.

2. Fukao T, Mitchell G, Sass JO, Hori T, Orii K, Aoyama Y. Ketone body metabolism and its defects. J Inherit Metab Dis 2014; 37: 541-551.

3. Daum RS, Lamm PH, Mamer OA, Scriver CR. A "new" disorder of isoleucine catabolism. Lancet 1971; 2: 1289-1290.

4. Masuno M, Kano M, Fukao T, et al. Chromosome mapping of the human mitochondrial acetoacetylcoenzyme A thiolase gene to 11q22.3-q23.1 by fluorescence in situ hybridization. Cytogenet Cell Genet 1992; 60: 121-122.

5. Estrella J, Wilcken B, Carpenter K, Bhattacharya $\mathrm{K}$, Tchan M, Wiley V. Expanded newborn screening in New South Wales: Missed cases. J Inherit Metab Dis 2014; 37: 881-887.

6. Sarafoglou K, Matern D, Redlinger-Grosse K, et al. Siblings with mitochondrial acetoacetyl-CoA thiolase deficiency not identified by newborn screening. Pediatrics 2011; 128: 246-250.

7. Fukao T, Yamaguchi S, Orii T, Schutgens RB, Osumi T, Hashimoto T. Identification of three mutant alleles of the gene for mitochondrial acetoacetyl-coenzyme A thiolase. A complete analysis of two generations of a family with 3-ketothiolase deficiency. J Clin Invest 1992; 89: 474-479.

8. Fukao T, Scriver CR, Kondo N. The clinical phenotype and outcome of mitochondrial acetoacetyl-CoA thiolase deficiency (BetaKetothiolase or T2 deficiency) in 26 enzymatically proved and mutation-defined patients. Mol Genet Metab 2001; 72: 109-114.

9. Ozand PT, Rashed M, Gascon GG, al Odaib A, Shums A, Nester M, Brismar J. 3-ketothiolase Deficiency: a review and four new patients with neurologic symptoms. Brain Dev 1994; 16: 3845.

10. Middleton B, Bartlett K, Romanos A, et al. 3-Ketothiolase deficiency. Eur J Pediatr 1986; 144: 586-589.

11. Buhaş D, Bernard G, Fukao T, Décarie JC, Chouinard S, Mitchell GA. A treatable new cause of chorea: beta-ketothiolase deficiency. Mov Disord 2013; 28: 1054-1060.

12. Sass JO, Grünert SC. Disorders of Ketone Body Metabolism. In: Blau N, Duran M, Gibson MK, et al. (eds). Physician's Guide to the Diagnosis, Treatment, and Follow-up of Inherited Metabolic Diseases. Berlin, Heidelberg: Springer-Verlag, 2014; 361-371. 
13. Henry CG, Strauss AW, Keating JP, Hillman RE. Congestive cardiomyopathy associated with beta-ketothiolase deficiency. J Pediatr 1981; 99: 754-757.

14. O'Neill ML, Kuo F, Saigal G. MRI of pallidal involvement in beta-ketothiolase deficiency. J Neuroimaging 2014; 24: 414-417.

15. Nyhan WL, Barshop BA, Al-Aqeel A. Mitochondrial acetoacetyl-CoA thiolase deficiency. In: Atlas of Inherited Metabolic Diseases (3rd ed). London: Hodder Arnold, 2012: 95-102.

16. Altintaş B, Teziç T, Coşkun T, Ozalp I, Kükner S, Kaya A. Beta-ketothiolase deficiency: A case report. Turk J Pediatr 1992; 34: 43-46.
17. Fukao T, Maruyama S, Ohura T, et al. Three Japanese patients with beta-ketothiolase deficiency who share a mutation, c.431A $>\mathrm{C}(\mathrm{H} 144 \mathrm{P})$ in ACAT1. Subtle abnormality in urinary organic acid analysis and blood acylcarnitine analysis using tandem MS spectrometry. JIMD Rep 2012; 3: 107-115.

18. Fukao T, Horikawa R, Naiki Y, et al. A novel mutation (c.951C $>\mathrm{T}$ ) in an exonic splicing enhancer results in exon 10 skipping in the human mitochondrial acetoacetyl-CoA thiolase gene. Mol Genet Metab 2010; 100: 339-344.

19. Otsuka H, Sasai H, Nakama M, et al. Exon 10 skipping in ACAT1 caused by a novel c.949G >A mutation located at an exonic splice enhancer site. Mol Med Rep 2016; 14: 4906-4910. 